\title{
Hubungan Framingham Risk Score dengan Derajat TIMI Risk Score pada Pasien Infark Miokard Akut dengan Elevasi Segmen ST di RSUP Prof. Dr. R. D. Kandou Periode Januari-September 2018
}

\author{
${ }^{1}$ Moh. Akbar R. Alitu \\ ${ }^{2}$ Edmond L. Jim \\ ${ }^{2}$ Victor F. Joseph
}

\author{
${ }^{1}$ Program Studi Pendidikan Dokter Fakultas Kedokteran Universitas Sam Ratulangi Manado \\ ${ }^{2}$ Bagian Ilmu Penyakit Jantung dan Pembuluh Darah Fakultas Kedokteran \\ Universitas Sam Ratulangi Manado \\ Email: akbaralitu@outlook.com
}

\begin{abstract}
Myocardial infarction (MI) is one of the main manifestations of coronary heart diseases. ST segment elevation myocardial infarction (STEMI) is a symptomatic clinical syndrome characterized by myocardial ischemia associated with persistent ST segment elevation. The Framingham risk score (FRS) is designed to predict the risk of death due to coronary heart disease and myocardial infarction meanwhile the TIMI risk score is used as a tool to determine the mortality risk of STEMI patients. This study was aimed to determine the relationship between the FRS and the degree of TIMI risk score in STEMI patients at Prof. Dr. R. D. Kandou Hospital Manado. This was a retrospective analytical study. Samples were patients diagnosed as STEMI at Prof. Dr. R. D. Kandou Hospital Manado from January to September 2018. There were 93 patients obtained by using total sampling. The Pearson correlation test of the relationship between the FRS and the degree of TIMI risk score in STEMI patients obtained an $\mathrm{r}$ of 0.097 with the $P$ value of 0.177 . Conclusion: There was no relationship between the Framingham risk score and the TIMI risk score among IMA-EST patients.
\end{abstract}

Keywords: myocardial infarction, Framingham risk score, TIMI risk score, STEMI

\begin{abstract}
Abstrak: Infark miokard adalah salah satu manifestasi utama penyakit jantung koroner (PJK). Infark miokard akut dengan elevasi segmen ST (IMA-EST) adalah sindrom klinis dengan gejala karakteristik iskemia miokard yang berhubungan dengan elevasi segmen ST persisten. Framingham risk score (FRS) dirancang untuk memrediksi risiko kematian karena PJK dan infark miokard. TIMI risk score digunakan sebagai alat untuk menentukan risiko mortalitas pasien IMA-EST. Penelitian ini bertujuan untuk mengetahui hubungan FRS dengan derajat TIMI risk score pada pasien IMA-EST di RSUP Prof. Dr. R. D. Kandou. Jenis penelitian ialah analitik retrospektif. Sampel penelitian ialah pasien IMA-EST di RSUP Prof. Dr. R. D. Kandou Manado periode Januari-September 2018 sebanyak 93 pasien diambil dengan total sampling. Hasil uji korelasi Pearson terhadap hubungan antara FRS dan TIMI risk score pada pasien IMA-EST mendapatkan $\mathrm{r}=0,097$ dengan nilai $P=0,177$. Simpulan: Tidak terdapat hubungan antara Framingham risk score dan TIMI risk score pada pasien IMA-EST.
\end{abstract}

Kata kunci: infark miokard, Framingham risk score, TIMI risk score, IMA-EST

Penyakit kardiovaskular merupakan masalah kesehatan masyarakat global yang berkontribusi terhadap 30\% kematian global dan $10 \%$ dari beban penyakit global.
Pada tahun 2005, dari total 58 juta kematian di seluruh dunia, 17 juta disebabkan oleh penyakit kardiovaskular, di antaranya, 7,6 juta disebabkan oleh penyakit jantung 
koroner (PJK). Infark miokard (MI) ialah salah satu dari lima manifestasi utama PJK, yaitu angina pektoris stabil, angina pektoris tidak stabil, MI, gagal jantung dan kematian mendadak. Yang termasuk dalam sindrom koroner akut ialah unstable angina, non ST-elevation myocardial infarction (IMA-NEST), ST-elevation myocardial infarction (IMA-EST), dan kematian jantung mendadak. ${ }^{1}$ Penyakit jantung iskemik sekarang menyumbang hampir 1,8 juta kematian per tahun, atau $20 \%$ dari semua kematian di Eropa, meskipun dengan variasi besar antar negara. $^{2}$

Infark miokard akut dengan elevasi segmen ST (IMA-EST) adalah sindrom klinis yang didefinisikan oleh gejala karakteristik iskemia miokard yang berhubungan dengan elevasi segmen ST persisten dan pelepasan biomarka nekrosis miokardial selanjutnya. ${ }^{3}$ Diagnosis IMAEST ditegakkan jika terdapat keluhan angina pektoris akut disertai elevasi segmen ST yang persisten di dua sadapan yang bersebelahan. ${ }^{4}$

Framingham risk score/FRS berasal dari kohort Framingham Heart Study (FHS) dan dirancang untuk memrediksi risiko 10 tahun dari kejadian koroner berat, termasuk kematian karena penyakit jantung koroner dan infark miokard non-fatal (MI) dengan mempertimbangkan ada tidaknya faktor-faktor risiko penting. ${ }^{5}$ FRS dihitung dengan mempertimbangkan usia, jenis kelamin, status merokok, kolesterol total, kolesterol high-density lipoprotein (HDL), dan tekanan darah sistolik. ${ }^{6}$

Skor risiko thrombolysis in myocardial infarction (TIMI) dikembangkan sebagai bedside tools untuk menentukan pasien IMA-EST yang memenuhi syarat untuk reperfusi dengan risiko mortalitasnya. Skor risiko TIMI telah terbukti memberikan diskriminasi yang baik dalam memrediksi kematian pada 30 hari dan bahkan hingga 365 hari. $^{7}$ Skor risiko TIMI adalah alat klinis yang kuat untuk prediksi risiko kematian pada pasien IMA-EST yang memenuhi syarat fibrinolitik. ${ }^{8}$ Pasien diklasifikasikan sebagai risiko rendah jika skor TIMI 0-4, menengah 5-8, dan berisiko tinggi jika skor TIMI $\geq 8$.

Penelitian ini bertujuan untuk mengetahui hubungan Framingham Risk Score dan derajat Timi Risk Score pada pasien IMA-EST di RSUP Prof. Dr. R. D. Kandou Manado.

\section{METODE PENELITIAN}

Jenis penelitian ini ialah analitik retrospektif. Penelitian dilakukan di Bagian CVBC RSUP Prof. Dr. R. D. Kandou Manado. Sampel penelitian ialah pasien IMA-EST di RSUP Prof. Dr. R. D. Kandou Manado periode Januari-September 2018, diambil dengan menggunakan total sampling. Kriteria inklusi berupa pasien yang didiagnosis dengan infark miokard akut dengan elevasi segmen ST, dan usia $>30$ tahun. Kriteria eksklusi ialah pasien yang skor TIMI dan data yang digunakan untuk mengukur FRS tidak lengkap.

Penelitian ini menggunakan data rekam medik pasien yang didiagnosis dengan IMA-EST. Nilai TIMI diambil langsung pada status pasien, sedangkan skor FRS didapatkan dengan menghitung faktor risiko yang ada di status pasien, kemudian diolah dan dilakukan uji korelasi.

\section{HASIL PENELITIAN DAN BAHASAN}

Total pasien IMA-EST yang dirawat di bagian CVBC RSUP Prof. Dr. R. D. Kandou selama bulan Januari-September 2018 sebanyak 116 pasien dan diambil 93 pasien yang memenuhi kriteria inklusi dan eksklusi.

Riwayat penyakit kardiovaskular menunjukkan ada tidaknya riwayat penyakit jantung kardiovaskular sebelumnya pada pasien IMA-EST. Pasien yang tidak memiliki riwayat penyakit kardiovaskular sebelumnya lebih banyak, yaitu sebanyak 85 pasien $(91,4 \%)$ (Tabel 1$)$.

Tabel 1. Riwayat PJK sebelumnya

\begin{tabular}{ccc}
\hline PJK & $\mathbf{N}$ & $\mathbf{\%}$ \\
\hline Tidak & 85 & 91,4 \\
Ya & 8 & 8,6 \\
Total & 93 & 100,0 \\
\hline
\end{tabular}


Status pulang menunjukkan keadaan pasien saat keluar dari perawatan Rumah Sakit. Pada Tabel 2 dapat dilihat bahwa pasien yang kembali pulang dalam keadaan hidup lebih banyak, yaitu sebanyak 88 pasien $(94,6 \%)$. Hasil ini sesuai dengan penelitian yang dilakukan oleh Ataollah, ${ }^{9}$ yang melaporkan tingkat mortalitas dari pasien IMA-EST yang menjalani primary $P C I$ sebesar $7 \%$ dalam 1 tahun pertama.

Tabel 2. Status pulang pasien IMA-EST

\begin{tabular}{ccc}
\hline Status pulang & $\mathbf{n}$ & $\mathbf{\%}$ \\
\hline Meninggal & 5 & 5,4 \\
Hidup & 88 & 94,6 \\
Total & 93 & 100,0 \\
\hline
\end{tabular}

Pada Tabel 3 dapat dilihat mayoritas pasien IMA-EST ialah laki-laki sebanyak 68 pasien $(73,1 \%)$ dan pasien perempuan 25 pasien $(26,9 \%)$. Hasil ini sesuai dengan penelitian mengenai jenis kelamin, usia, dan risiko pasien IMA-EST di Finlandia selama tahun 2001-2008 dengan jumlah pasien 27.993 orang. Didapatkan pasien laki-laki lebih banyak dengan $65,9 \%$ pasien laki-laki dan $34,1 \%$ pasien perempuan. ${ }^{10}$

Tabel 3 Jenis kelamin pasien IMA-EST

\begin{tabular}{ccc}
\hline Jenis kelamin & $\mathbf{n}$ & $\mathbf{\%}$ \\
\hline Laki-laki & 68 & 73,1 \\
Perempuan & 25 & 26,9 \\
Total & 93 & 100,0 \\
\hline
\end{tabular}

Pada Tabel 4 dapat dilihat bahwa kelompok usia 55-59 tahun memiliki jumlah pasien terbanyak, yaitu 15 pasien $(16,1 \%)$. Kelompok usia 35-39 tahun memiliki jumlah pasien yang paling sedikit, sebanyak 3 pasien (3,2\%). Rerata usia pasien IMA-EST ialah 58,47 tahun.

Hasil ini sesuai dengan penelitian mengenai jenis kelamin, usia, dan risiko pasien IMA-EST di Finlandia selama tahun 2001-2008, dimana tingkat insiden IMAEST menin-gkat sekitar $41 \%$ untuk setiap peningkatan usia sebanyak 5 tahun. ${ }^{10}$
Tabel 4. Kelompok usia pasien IMA-EST

\begin{tabular}{ccc}
\hline $\begin{array}{c}\text { Kelompok usia } \\
\text { (tahun) }\end{array}$ & n & \% \\
\hline $35-39$ & 3 & 3,2 \\
$40-44$ & 8 & 8,6 \\
$45-49$ & 12 & 12,9 \\
$50-54$ & 14 & 15,1 \\
$55-59$ & 15 & 16,1 \\
$60-64$ & 10 & 10,8 \\
$65-69$ & 13 & 14,0 \\
$70-74$ & 10 & 10,8 \\
$>75$ & 8 & 8,6 \\
Total & 93 & 100,0 \\
Rerata & 58,47 & \\
\hline
\end{tabular}

Lokasi IMA-EST menunjukkan lokasi infark pada jantung. Data ini diambil dari diagnosis pada status pulang rekam medik pasien. Lokasi infark terbanyak pada IMAEST anteroseptal sebanyak 35 pasien $(37,6 \%)$ dan pada IMA-EST inferior sebanyak 31 pasien $(33,3 \%)$ Penelitian mengenai mortalitas dan tingkat rasio dari infark miokard berdasarkan lokasi anatomis terhadap 4 komunitas di Amerika Serikat dari tahun 1986 sampai tahun 2008, mendapatkan bahwa $37,2 \%$ dari infark miokard ialah IMA-EST inferior, 32,8\% IMA-EST anterior, 16,8\% IMA-EST infark multipel, dan 13,2\% IMA-EST lateral. ${ }^{11}$

Pada Tabel 6 didapatkan mayoritas pasien memiliki low TIMI risk score (TIMI 1-4) sebanyak 49 pasien $(52,7 \%)$ dan paling sedikit pada high TIMI risk score $>8$ sebanyak 6 pasien $(6,5 \%)$.

Pada Tabel 7 didapatkan FRS terbanyak terdapat pada FRS dengan nilai 14, sebanyak 12 pasien (12,9\%). Setelah didapatkan nilai dari FRS dan TIMI risk score dari pasien, selanjutnya diperlukan analisis korelasi untuk menentukan hubungan dari kedua Skor tersebut.

Hubungan antara TIMI risk score dan FRS diuji dengan uji korelasi Pearson. Hasil uji ini mendapatkan $\mathrm{r}=0,097$ dengan nilai $P=0,177$. Hubungan kedua skor ini dapat dilihat pada Gambar 1. Hasil ini menyatakan tidak terdapat hubungan bermakna antara TIMI risk score dan FRS, walaupun skoring dari FRS dan TIMI 
memiliki 3 variabel sama yang digunakan dalam skoring, yaitu usia, hipertensi, dan diabetes. Penelitian oleh Selvarajah et al, ${ }^{12}$ menyatakan bahwa FRS dapat memperkirakan tingkat mortalitas kardiovaskular dalam 5 tahun.

Tabel 5. Lokasi infark pada pasien IMA-EST

\begin{tabular}{lcc}
\hline \multicolumn{1}{c}{ Lokasi Infark } & n & \% \\
\hline IMA-EST anterior & 5 & 5.4 \\
IMA-EST abteroekstensif & 13 & 14.0 \\
IMA-EST anteroseptal & 35 & 37.6 \\
IMA-EST inferior & 31 & 33.3 \\
IMA-EST inferolateral + anterior & 1 & 1.1 \\
IMA-EST infreoposterior & 8 & 8.6 \\
Total & 93 & 100.0 \\
\hline
\end{tabular}

Tabel 6. TIMI risk score

\begin{tabular}{ccc}
\hline TIMI risk & n & \% \\
\hline Low & 49 & 52,7 \\
Medium & 38 & 42,9 \\
High & 6 & 6,5 \\
Total & 93 & 100 \\
\hline
\end{tabular}

Tabel 7. Framingham risk score

\begin{tabular}{ccc}
\hline FRS & Frekuensi & \% \\
\hline 3 & 1 & 1,1 \\
4 & 1 & 1,1 \\
6 & 1 & 1,1 \\
7 & 8 & 8,6 \\
8 & 3 & 3,2 \\
9 & 4 & 4,3 \\
10 & 6 & 6,5 \\
11 & 9 & 9,7 \\
12 & 8 & 8,6 \\
13 & 8 & 8,6 \\
14 & 12 & 12,9 \\
15 & 9 & 9,7 \\
16 & 1 & 1,1 \\
17 & 8 & 8,6 \\
18 & 3 & 3,2 \\
19 & 3 & 3,2 \\
20 & 2 & 2,2 \\
21 & 3 & 3,2 \\
23 & 2 & 2,2 \\
26 & 1 & 1,1 \\
Total & 93 & 100,0 \\
\hline
\end{tabular}

Tabel 8. Hasil uji korelasi Pearson

\begin{tabular}{lcc}
\hline & FRS \\
\hline TIMI & Pearson correlation &, 097 \\
risk scoreSig. (1-tailed) &, 177 \\
\multicolumn{2}{c}{$\mathrm{N}$} & 93 \\
\hline
\end{tabular}

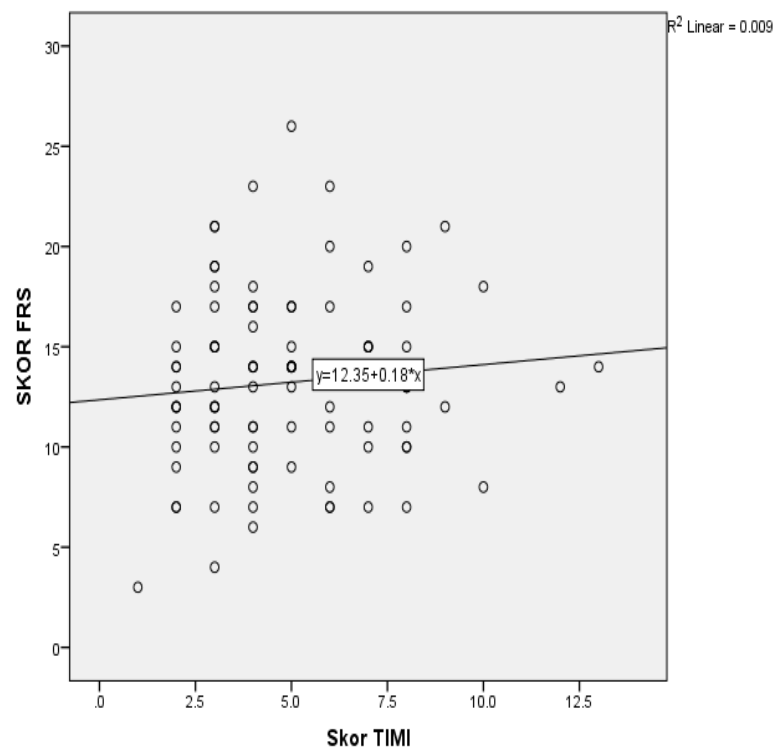

Gambar 1. Hubungan antara TIMI risk score dan FRS diuji dengan uji korelasi Pearson

\section{SIMPULAN}

Berdasarkan hasil penelitian ini dapat disimpulkan bahwa pada pasien IMA-EST di RSUP Prof. Dr. R. D. Kandou tidak terdapat hubungan antara Framingham risk score dan TIMI risk score. 


\section{SARAN}

Diperlukan validasi dari skoring TIMI risk score dan Framingham risk score pada populasi masyarakat indonesia.

Diperlukan penelitian lanjutan dengan jangka waktu lebih panjang dan jumlah sampel lebih banyak, untuk menilai hubungan antara Framingham risk score dan TIMI risk score terhadap pasien IMAEST.

\section{DAFTAR PUSTAKA}

1. Thygesen K, Alpert JS, Jaffe AS, Chaitman BR, Bax JJ, Morrow DA, et al. Fourth universal definition of myocardial infarction (2018). Eur Heart J. 2018; (August):1-33.

2. Ibanez B, James S, Agewall S, Antunes MJ, Bucciarelli-Ducci C, Bueno $\mathbf{H}$, et al. 2017 ESC Guidelines for the management of acute myocardial infarction in patients presenting with ST-segment elevation. Eur Heart J. 2018;39(2):11977.

3. Hwang C. ECG diagnosis: ST-elevation myocardial infarction. Perm J. 2014; 18(2):e133-e133.

4. PERKI. Pedoman Tatalaksana Sindrom Koroner Akut (4th ed), 2018.

5. D'Agostino RB, Vasan RS, Pencina MJ, Wolf PA, Cobain M, Massaro JM, et al. General cardiovascular risk profile for use in primary care: The Framingham heart study. Circulation. 2008;117(6): 743-53.

6. Lee GKM, Lee L-C, Liu CWY, Lim SL, Shi L-M, Ong H-Y, et al. Framingham risk score inadequately predicts cardiac risk in young patients presenting with a first myocardial infarction. Ann Acad Med Singapore. 2010;39(3):163-7.

7. Selvarajah S, Fong AYY, Selvaraj G, Haniff J, Uiterwaal CSPM, Bots ML. An Asian validation of the TIMI risk score for ST-segment elevation myocardial infarction. PLoS One. 2012;7(7):1-7.

8. Morrow DA, Antman EM, Parsons L, De Lemos JA, Cannon CP, Giugliano RP, et al. Application of the TIMI risk score for ST-elevation MI in the National Registry of Myocardial Infarction 3. J Am Med Assoc. 2001;286(11):1356-9.

9. Doost Hosseiny A, Moloi S, Chandrasekhar J, Farshid A. Mortality pattern and cause of death in a long-term follow-up of patients with STEMI treated with primary PCI. Open Heart. 2016;3(1):e000405.

10. Kytö V, Sipilä J, Rautava P. Gender, age and risk of ST segment elevation myocardial infarction. Eur J Clin Invest. 2014;44(10):902-9.

11. Newman JD, Shimbo D, Baggett C, Liu X, Crow R, Abraham JM, et al. Trends in myocardial infarction rates and case fatality by anatomical location in four United States communities, 1987 to 2008 (from the Atherosclerosis Risk in Communities Study). Am J Cardiol. 2013;112(11):1714-9.

12. Selvarajah S, Kaur G, Haniff J, Cheong KC, Hiong TG, van der Graaf Y, et al. Comparison of the Framingham Risk Score, SCORE and WHO/ISH cardiovascular risk prediction models in an Asian population. Int J Cardiol. 2014; 176(1):211-8. 